\title{
Suppression of phorbol-12-myristate-13-acetate-induced tumor cell invasion by apigenin via the inhibition of p38 mitogen-activated protein kinase-dependent matrix metalloproteinase-9 expression
}

\author{
HYO-JEONG NOH, EON-GI SUNG, JOO-YOUNG KIM, TAE-JIN LEE and IN-HWAN SONG \\ Department of Anatomy, College of Medicine, Yeungnam University, \\ 317-1 Daemyung-Dong Nam-Gu, Daegu 705-717, Korea
}

Received January 15, 2010; Accepted March 29, 2010

DOI: $10.3892 /$ or 00000857

\begin{abstract}
Apigenin has special interest for the development of chemopreventive agents against cancer because it is a widely distributed plant flavonoid that has antitumor properties. In this study, we investigated the apigenin effects on the protease-mediated invasiveness in human metastatic cancer cell lines Caski, SK-Hep1, and MDA-231. We found that apigenin markedly inhibits the phorbol-12-myristate-13acetate (PMA)-induced increase in MMP-9 expression and activity in several cancer cell lines. These effects of apigenin are dose-dependent and correlate with the suppression of MMP-9 mRNA expression levels. PMA caused about a 5fold induction in MMP-9 promoter activity, which was also suppressed by apigenin treatment in Caski cells. We found that apigenin could inhibit PMA-induced phosphorylation of p38 mitogen-activated protein kinase (p38 MAPK), which was involved in the down-regulation of the expression of matrix metalloproteinase-9 (MMP-9) at mRNA levels. Furthermore, the treatment of inhibitors specific for $\mathrm{p} 38$ MAPK (SB203580) to Caski cells caused the reduction of MMP-9 expression. Restoration of p38 expression partly increased PMA-induced MMP-9 secretion blocked by apigenin treatment in Caski cells. These results showed apigenin might inhibit the invasion and migration abilities of Caski cells by reducing the MMP-9 expression through suppressing the p38 MAPK signaling pathway. These findings indicate that apigenin might be a useful strategy for controlling metastasis and the invasiveness of tumors.
\end{abstract}

\section{Introduction}

Molecular mechanisms of tumor cell invasion and metastasis are complex processes involving action of extracellular matrix

Correspondence to: Dr T.-J. Lee or Dr I.-H. Song, Department of Anatomy, College of Medicine, Yeungnam University, 317-1 Daemyung-Dong Nam-Gu, Daegu 705-717, Korea

E-mail: tjlee@med.yu.ac.kr

E-mail: ihsong@med.yu.ac.kr

Key words: apigenin, matrix metalloproteinase-9, Caski, p38, invasion
(ECM)-degrading proteinase and migration through the ECM (1-3). Matrix metalloproteinases (MMPs) are enzymes involved in ECM degradation and play a crucial role in the process of cancer invasion and metastasis (4-6). Among human MMPs reported previously, gelatinase-A (MMP-2) and gelatinase-B (MMP-9) are key enzymes for degrading type IV collagen, which is a major component of the basement membrane $(7,8)$. Expression levels of MMP-2 and MMP-9 are associated with tumor metastasis for various human cancers $(9,10)$. Previous studies showed a positive correlation between expression of MMP-9 and tumor metastasis for colorectal cancer as well as several types of epithelial cancer $(11,12)$; thus, inhibition of MMP activity has been adopted as an anticancer therapeutic strategy.

Apigenin is one of the flavonoids that is found in high amounts among several herbs and common fruits such as parsley, onions, oranges, tea, chamomile, thyme, and peppermint (13). Apigenin has gained particular interest in recent years as a beneficial and health promoting agent because of its low intrinsic toxicity and differential effects in normal versus cancer cells compared with other structurally related flavonoids (13). However, apigenin inhibits motility and invasiveness of carcinoma cells in vitro, inhibitory mechanism(s) of apigenin on PMA-induced motility and invasiveness as well as PMA-induced MMP-9 activation of carcinoma cells is/are not well defined. The aim of this study was to evaluate the inhibitory effect of apigenin on PMApromoting invasion as well as MMP-9 expression and activity in Caski cells. Furthermore, we determined whether the inhibition of these MMPs by apigenin treatment is mediated through the cellular signaling pathways such as by inhibition of the phosphorylation of p38 MAPK protein pathways of Caski cells.

\section{Materials and methods}

Cells and materials. Human Caski, SK-Hep-1, and MDA-231 cells were obtained from the American Type Culture Collection (Rockville, MD). The culture medium used throughout these experiments was Dulbecco's modified Eagle's medium (DMEM), supplemented with $2 \mathrm{mM}$ L-glutamine, $100 \mathrm{U} / \mathrm{ml}$ penicillin, $100 \mu \mathrm{g} / \mathrm{ml}$ streptomycin, and 10\% FBS. Apigenin 
was purchased from Calbiochem (La Jolla, CA). Lipofectamine reagent was obtained from Life Technologies, Inc. (Rockville, MA). Luciferase assay and ß-galactosidase assay systems were purchased from Promega (Madison, WI).

Cell viability assay. The effect of fisetin on cell viability was determined by [3-(4,5-dimethylthiazol-2-yl)-2,5-diphenyl tetrazoliumbromide] (MTT) assay. Cells were seeded into 96-well plates at a density of $3 \times 10^{4}$ cells $/ 100 \mu \mathrm{l} /$ well. After 24-h growth, cells were treated with different concentrations of apigenin ranging from 5 to $20 \mu \mathrm{M}$ for $24 \mathrm{~h}$. After the exposure period, medium was removed and the cells were washed with PBS. Then, the medium was changed and incubated with MTT solution (Promega, Southampton, UK) for $4 \mathrm{~h}$. The number of viable cells was directly proportional to the production of formazan, which was then dissolved with DMSO, and measured spectrophotometrically at $563 \mathrm{~nm}$. The percentage of viable cells was estimated by comparison with untreated control cells.

Gelatin substrate gel zymography. To determine the effect of apigenin on PMA-induced MMP-9 activity, cells were treated with various concentrations of apigenin in the presence of 75 nM PMA and then MMP-9 expression was evaluated by zymography. Zymography was performed by the procedure described by Overall et al (14) with minor modification. The human cell lines were suspended in their respective medium containing $10 \%$ fetal bovine serum and plated at $8 \times 10^{5}$ cells. Dishes were incubated until $\sim 80 \%$ confluency, the medium was aspirated, and then fresh serum-free medium was added to each dish, with and without apigenin. Supernatants were collected after incubation for $24 \mathrm{~h}$. Supernatants were subjected to SDS-PAGE in $10 \%$ polyacrylamide gels that were copolymerized with $1 \mathrm{mg} / \mathrm{ml}$ of gelatin. After electrophoresis, the gels were washed several times in $2.5 \%$ Triton $\mathrm{X}-100$ for $1 \mathrm{~h}$ at room temperature to remove the SDS, then incubated for $24-48 \mathrm{~h}$ at $37^{\circ} \mathrm{C}$ in buffer containing $5 \mathrm{mM} \mathrm{CaCl}_{2}$ and $1 \mu \mathrm{M} \mathrm{ZnCl}_{2}$. The gels were stained with Coomassie blue $(0.25 \%)$ for $30 \mathrm{~min}$, and then destained for $1 \mathrm{~h}$ in a solution of acetic acid and methanol. The proteolytic activity was evidenced as clear bands (zones of gelatin degradation) against the blue background of stained gelatin.

Plasmids, transfection, and luciferase gene assays. MMP-9 reporter construct were kindly provided by Dr T.K. Kwon (School of Medicine, Keimyung University, Korea). In brief, cells were seeded onto six-well plates at a density of $5 \times 10^{5}$ cells/well and grown overnight. Cells were transfected with $2 \mu \mathrm{g}$ of MMP-9 promoter construct and $1 \mu \mathrm{g}$ of the pCMV-B-galactosidase plasmid for $5 \mathrm{~h}$ by the Lipofectamine 2000 method. After transfection, cells were cultured in $10 \%$ FCS medium with vehicle (DMSO) or drugs for $24 \mathrm{~h}$. Luciferase and $\beta$-galactosidase activities were assayed according to the manufacturer's protocol (Promega). Luciferase activity was normalized for $\beta$-galactosidase activity in cell lysate and expressed as an average of three independent experiments.

RNA isolation and RT-PCR. To determine whether the reduced amounts of MMP-9 activity were a result of decreased levels

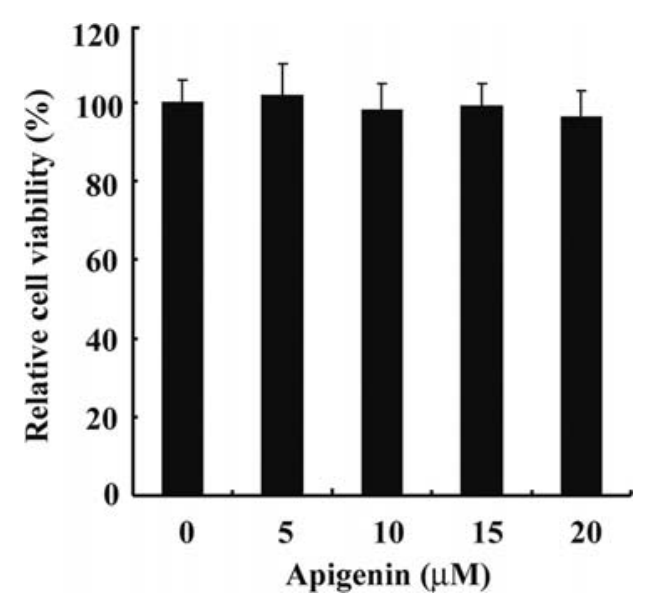

Figure 1. Effects of various concentrations of apigenin on cell viability in cultured Caski cells. The proliferation of cell lines were quantified by the cell survival rate after $24 \mathrm{~h}$ in doses of apigenin ranging from 1 to $5 \mu \mathrm{M}$ assessed by MTT assay. Relative cell viability in apigenin-treated cells was expressed as a ratio of the values of the control cells. Results are shown as mean \pm SE. The bars represent the standard error of the experiment.

of mRNA encoding this collagenase, we compared the levels of MMP-9 in several cancer cells, which were treated with or without various concentrations of apigenin in the presence of 75 nM PMA. MMP-9 mRNA expression was determined by RT-PCR. Total cellular RNA was extracted from Caski cells using the TRIzol reagent (Life Technologies, Inc.). A cDNA was synthesized from $2 \mu \mathrm{g}$ of total RNA using Moloney murine leukemia virus reverse transcriptase (Life Technologies, Inc., Gaithersburg, MD). The sequences of the sense and anti-sense primer for MMP-9 were 5'-CACTGTCCACCCC TCAGAGC-3' and 5'-GCCACTTGTCGGCGATAAGG-3', respectively. PCR products were analyzed by agarose gel electrophoresis and visualized by ethidium bromide.

Invasion assay. Cells/chamber $\left(5 \times 10^{4}\right)$ were used for each invasion assay. Invasion assays were performed using modified Boyden chambers with polycarbonate nucleopore membrane (Corning, Corning, NY). Precoated filters (6.5-mm in diameter, $8 \mu \mathrm{m}$ pore-size, Matrigel $\left.100 \mu \mathrm{g} / \mathrm{cm}^{2}\right)$ were rehydrated with $250 \mu 1$ of medium, and $5 \times 10^{4}$ cells in $200 \mu 1$ medium with or without apigenin in the presence of PMA were seeded into the upper part of each chamber. After incubation for $24 \mathrm{~h}$ at $37^{\circ} \mathrm{C}$, non-migratory cells on the upper surface of the filter were wiped with a cotton swab, and migrated cells on the lower surface of the filter were fixed and stained with $0.125 \%$ Coomassie Blue in a methanol:acetic acid:water mixture $(45: 10: 45, \mathrm{v} / \mathrm{v} / \mathrm{v})$. Random fields were counted under a light microscope.

\section{Results}

Effect of apigenin on the cell viability of cancer cells. We checked the cell viability of various concentrations $(0-20 \mu \mathrm{M})$ of apigenin on human cervical cancer Caski cells. Compared with that of controls, the remaining cell viability was not markedly altered by apigenin, even at a concentration up to $10 \mu \mathrm{M}$ in Caski cells (Fig. 1). Therefore, it was clear that the 
A

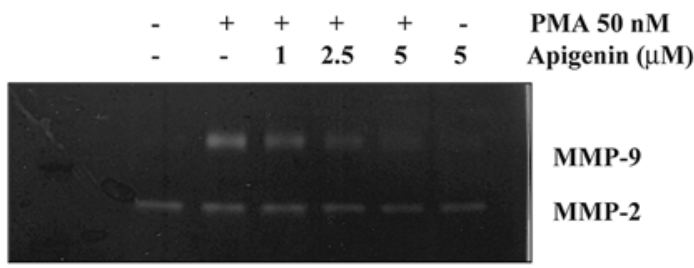

B

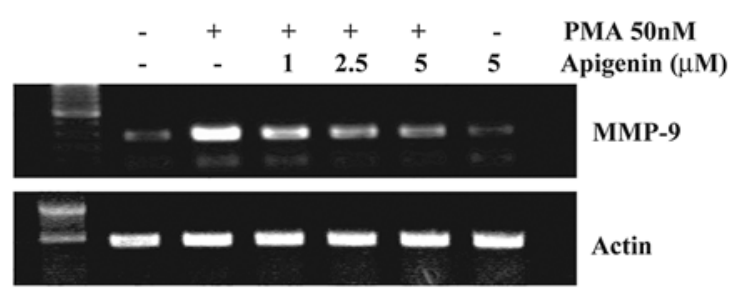

C

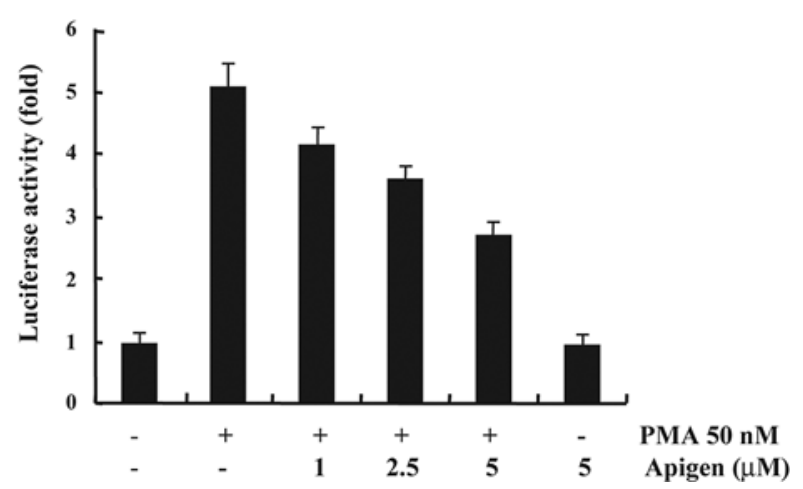

Figure. 2. Effect of apigenin on MMP-9 activity and expression in Caski cells. (A) Cells were treated with various concentrations $(1-5 \mu \mathrm{M})$ of apigenin for $24 \mathrm{~h}$. The conditioned media were collected and MMP-2 and MMP-9 activities were determined by gelatin and casein zymography. (B) Caski cells were treated with or without various concentrations of apigenin in the presence of PMA $(75 \mathrm{nM})$. Total RNA was isolated, and RT-PCR analysis was performed. The MMP-9 mRNA levels shown are representative of three independent experiments. (C) WT-MMP-9 promoter-containing reporter vector was transfected and treated with various concentrations of apigenin in the absence or presence of PMA $(75 \mathrm{nM})$. The cells were lysed and luciferase activity measured. Results are shown as mean \pm SE. The bars represent the standard error of the experiment.

treatment of apigenin, at concentrations ranging from 0 to $20 \mu \mathrm{M}$, has no cytotoxic effects to Caski cells for $24 \mathrm{~h}$.

Effect of apigenin on MMP-9 activity. Caski cells, released basal levels of MMP-9 when cultured in serum-free medium, were treated with PMA for $24 \mathrm{~h}$. Although the level of MMP-2 expression was not significantly altered by PMA, PMA induced the expression and secretion of large amounts of latent MMP-9 as determined by gelatin zymography (Fig. 2A). As shown in Fig. 2A, apigenin decreased PMA-induced MMP-9 activity in a dose-dependent manner, whereas the activity of a control metalloproteinase, of which the size was identical to the Mr 72,000 type IV collagenase MMP-2 (15), was not reduced in apigenin-treated cells.

Repression of PMA-induced MMP-9 transcription by apigenin. Treatment of Caski cells with apigenin also induced a decrease in the levels of PMA-stimulated MMP-9 mRNA (Fig. 2B). RT-PCR showed that steady-state MMP-9 mRNA levels were
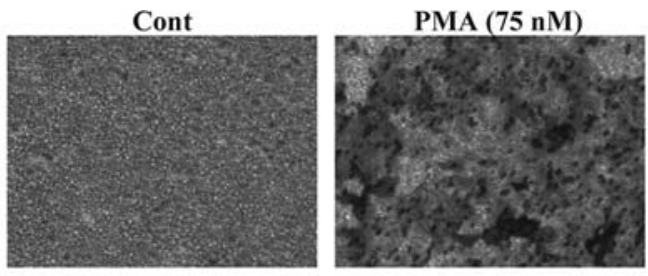

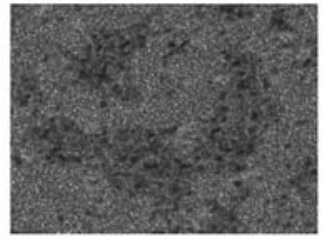

PMA + Apigenin

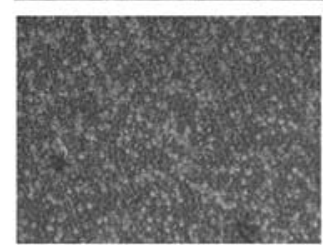

Apigenin $(5 \mu \mathrm{M})$

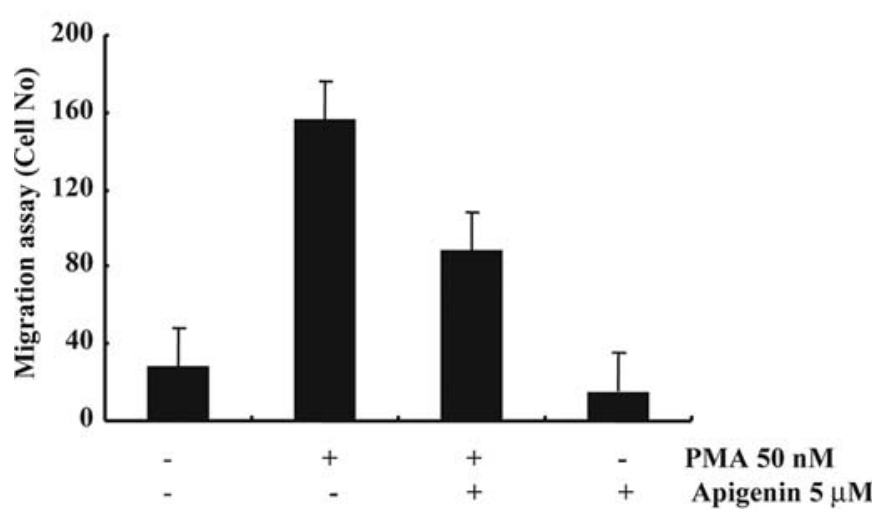

Figure 3. Effect of apigenin on Matrigel invasion by Caski cells. For invasion assay, the lower and upper parts of Transwells were coated with Matrigel. Caski cells cultured in the presence or absence of either PMA or apigenin at indicated concentrations were placed in the upper well. Invasiveness of the cells was determined by measuring the ability to pass through a layer of Matrigel-coated filter. After $24 \mathrm{~h}$, cells on the bottom side of the filter were fixed, stained, and counted as described in Materials and methods. Data represent the mean of at least three independent experiments. The bars represent the standard error of the experiment.

lower in apigenin-treated cells compared with non-treated cells. The effect of apigenin on MMP-9 expression was additionally investigated using HEK293 cells transiently transfected with a luciferase reporter gene linked to the $0.7-\mathrm{kb}$ fragment of MMP-9 promoter sequence. As shown in Fig. 2C, luciferase gene expression was activated up to 5-fold in these cells treated with PMA compared with untreated cells. Treatment of cells with apigenin $(5 \mu \mathrm{M})$ decreased PMA-mediated luciferase activity in a dose-dependent manner (Fig. 2C).

Effects of apigenin on the migration of Caski cells. We next examined the effect of apigenin on Caski cell invasion assay. As shown in Fig. 3, $5 \mu \mathrm{M}$ apigenin reduced the PMAinduced invasiveness of these cells by $\sim 50 \%$ compared with that of PMA-treated cells, although invasion was still reduced in the presence of apigenin. Therefore, the effect of apigenin on in vitro invasion inhibition was correlated with its effect on MMP-9 inhibition.

Apigenin inhibits PMA-induced secretion of MMP-9 and phosphorylation of p38 in Caski cells. In the next step, we examined the activation of the different mitogen-activated 
A

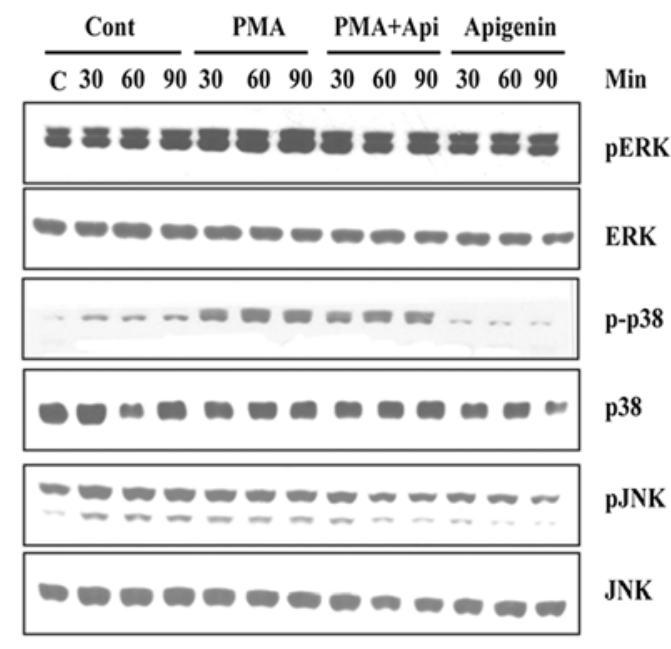

B

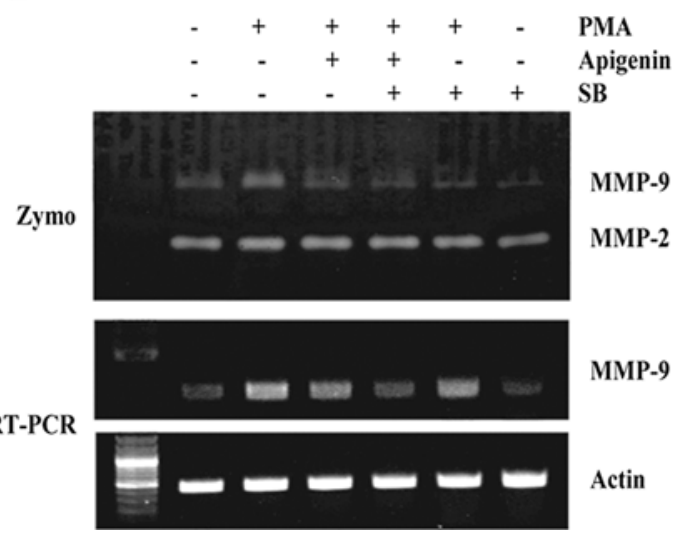

C

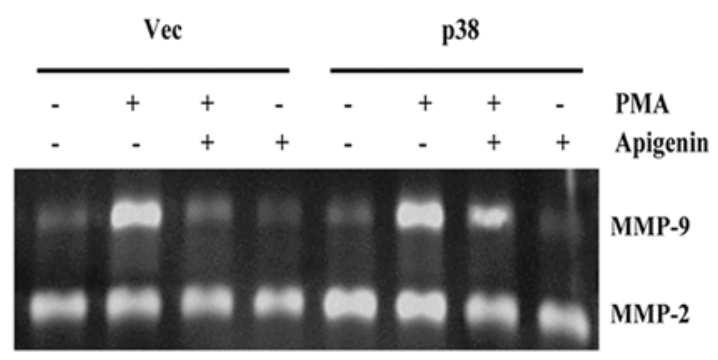

D

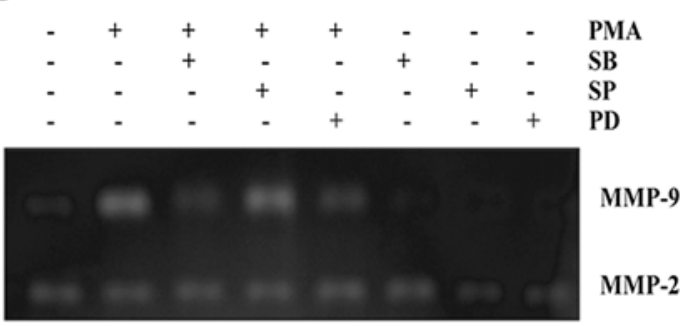

Figure 4. Apigenin inhibits PMA-induced secretion of MMP-9 and phosphorylation of p38 in Caski cells. (A) Caski cells were treated with vehicle, PMA (75 nM), apigenin $(5 \mu \mathrm{M})$ and PMA $(75 \mathrm{nM})$ plus apigenin $(5 \mu \mathrm{M})$ for indicated times. Equal amounts of cell lysates (40 $\mu \mathrm{g})$ were subjected to electrophoresis and analysed by immunoblotting using phosphorylation state-specific antibodies. To ascertain that the total level of each MAPK did not change, blots were stripped and reprobed with the antibodies raised against the corresponding phosphorylation-independent MAPK. (B) Caski cells were treated with vehicle, PMA (75 nM), apigenin $(5 \mu \mathrm{M})$, SB203580 $(20 \mu \mathrm{M})$, and PMA plus apigenin or PMA plus apigenin plus SB203580 for 24 h. MMP-9 activity or mRNA expression were determined as described above. (C) Ectopic expression of p38 attenuated PMA-induced MMP-9 secretion in Caski cells. Caski cells were transiently transfected with p38 expression vector and empty vector (pCMV) and treated with PMA in the presence or absence of apigenin for $24 \mathrm{~h}$. Afterward, the culture medium was subjected to gelatin and casein zymography to analyze the activities of MMP-2 and MMP-9. (D) Cells were seeded onto 6-well plates and pre-treated with SB203580, PD98059, and SP600125 for $1 \mathrm{~h}$ and then incubated in the presence or absence of apigenin for 24 h. Afterward, the culture medium was subjected to gelatin and casein zymography to analyze the activities of MMP-2 and MMP-9.

protein kinase (MAPK) cascades by PMA and potential action of apigenin. We found that the phosphorylation of ERK appears after $30 \mathrm{~min}$ of PMA stimulation (Fig. 4A). PMAinduced ERK phosphorylation was partly inhibited by apigenin treatment, whereas apigenin on its own did not show any effect on the phosphorylation status of ERK. The treatment of Caski cells with PMA also increased the levels of phosphorylation of p38 compared with control after PMA stimulation, which was markedly attenuated by apigenin treatment. Although the treatment of Caski cells with PMA did not alter the levels of phosphorylation of JNK compared with control, apigenin alone showed the inhibitory effect on the phosphorylation status of JNK. Since PMA-induced p38 phosphorylation was strongly inhibited by apigenin, we checked whether apigenin plus p38 inhibitor SB203580 could additively down-regulate MMP-9 expression which is enhanced by PMA treatment at transcription level.

The combination treatment of SB203580 and apigenin inhibited MMP-9 activity and mRNA expression more compared with single treatment with SB203580 or apigenin (Fig. 4B). To evaluate whether the decreased PMA-induced MMP-9 secretion by apigenin was related to P38 signaling pathway, Caski cells were transiently transfected with empty vector and p38 expression vector. Treatment with apigenin in PMA-treated Caski cells that were transfected with empty vector led to decrease of MMP-9 secretion, which were slightly blocked by ectopic expression of p38 (Fig. 4C). This result indicated that the decrease in PMA-induced MMP-9 secretion by apigenin was related to the inhibition of $\mathrm{p} 38$ signaling pathway in Caski cells. 
A
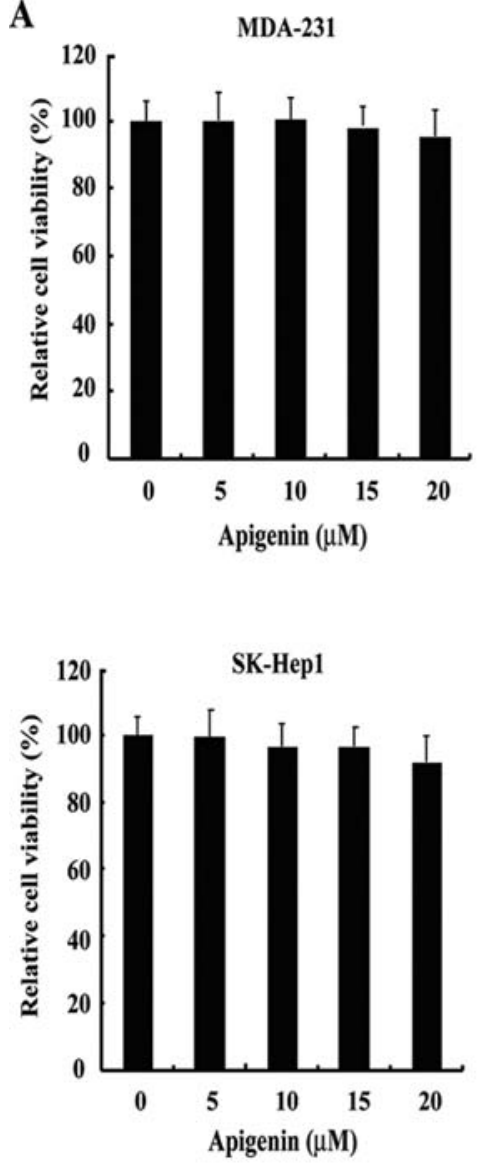

B

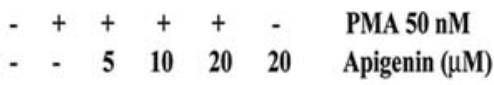

MDA-231

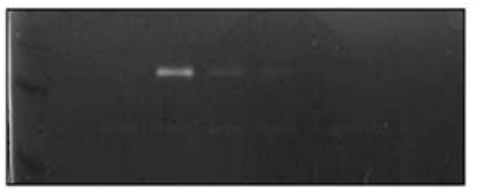

MMP-9

MMP-2

SK-Hep1

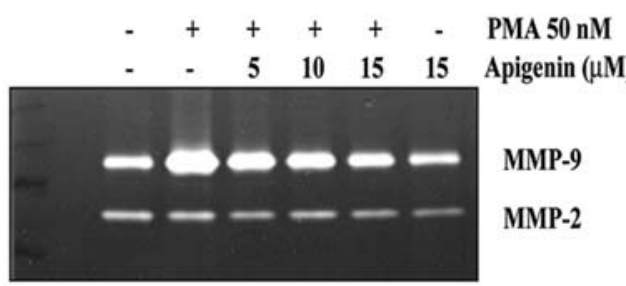

C

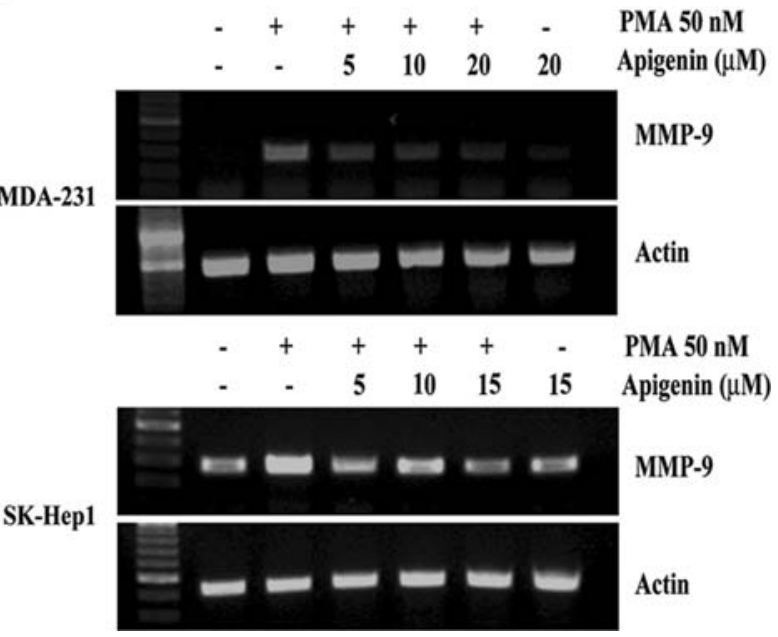

Figure 5. Apigenin inhibits PMA-induced MMP-9 expression and activity in several types of metastatic cancer cells. (A) The proliferation of cell lines (MDA-231 and SK-Hep1) were quantified by the cell survival rate after 24 in doses of apigenin ranging from 5 to $20 \mu$ M assessed by MTT assay. Relative cell viability in apigenin-treated cells was expressed as a ratio of the values of control cell. Results are shown as mean \pm SE. The bars represent the standard error of the experiment. (B) MDA-231 and SK-Hep1 cells were treated with various concentrations (5-20 $\mu \mathrm{M})$ of apigenin for $24 \mathrm{~h}$. The conditioned media were collected and MMP-2 and MMP-9 activities were determined by gelatin and casein zymography. (C) MDA-231 and SK-Hep1 cells were treated with or without various concentrations of apigenin in the presence of PMA (75 nM). Total RNA was isolated, and RT-PCR analysis was performed. The MMP-9 mRNA levels shown are representative of three independent experiments.

Collectively, apigenin inhibited PMA-induced secretion of MMP-9 and mRNA expression which was regulated at transcriptional level and PMA-prompting MMP-9 secretion via blocking p38 signaling pathway in Caski cells. In order to further investigate whether the inhibition of PMA-induced MMP-9 activation was mainly through the ERK or p38 MAPK signaling pathway, Caski cells were pretreated with a p38 inhibitor (SB203580; $20 \mu \mathrm{M}$ ) or ERK inhibitor (PD98059) for $1 \mathrm{~h}$ and then incubated with or without PMA for $24 \mathrm{~h}$. As shown in Fig. 4D, gelatin zymography assay showed the pretreatment with SB203580 or PD98059 reduced the MMP-9 activity induced by PMA, respectively. These results indicated that the PMA-induced MMP-9 activation occurred through p38 or ERK activation in Caski cells.

Apigenin inhibits PMA-induced MMP-9 expression and activity in several metastatic cancer cells. We further investigated whether apigenin attenuates PMA-induced MMP-9 expression and activity in other human metastatic cancer cell types. As shown in Fig. 5A, apigenin did not markedly influence cell viability in MDA-231 and SK-Hep1 cells at concentration range from 5 to $20 \mu \mathrm{M}$. However, apigenin decreased PMA-induced MMP-9 activity in a dose-dependent manner in both cell lines (Fig. 5B). Furthermore, treatment of MDA-231 and SK-Hep1 cells with apigenin also induced a decrease in the levels of PMA-stimulated MMP-9 mRNA in a dose-dependent manner (Fig. 5C).

\section{Discussion}

Metastasis of cancer cells is a complex multistep process, which is regarded as the important biological characteristic of advanced and aggressive cancers (16). During the process of metastasis, the invasion and migration of cancer cells is the most important step. MMPs play a major role in promoting tumor metastasis, and overexpression of MMP-9 has been associated with the progression and invasion of tumors $(4,17,18)$. Therefore, an agent that could efficiently 
inhibit MMP-9 expression and activity would interfere with the invasion of the cancer cells thus giving therapeutic and/or adjuvant therapeutic effects against human metastatic cancer cells.

Recently, considerable attention has been devoted to identifying plant-derived dietary agents that interfere with tumor metastasis via inhibiting MMP-9 expression and activity because of their non-toxicity and biocompatibility $(13,19-22)$. It has been reported that low-molecular-weight apigenin is useful in preventing tumor growth in many different types of human cancers $(13,23,24)$. However, the precise actions of apigenin on the invasion and migration of human cancer cells including cervical, breast, and hepatoma cancer cells and the associated signaling pathways have not been reported. In this study, we found that apigenin suppressed PMA-enhanced MMP-9 secretion, mRNA, and transcriptional activity as well as PMA-induced invasion in cervical cancer cells.

Under standard culture conditions, Caski, MDA-231, and SK-Hep1 cells secreted a detectable level of MMP-9, which were up-regulated by PMA treatment. Our results show that apigenin, even though no effect on the expression level and basal secretion of MMP-9, totally abolished the response to PMA stimulation in those cancer cells. Our results are in agreement with the observations that apigenin blocked PMAinduced up-regulation of MMP-9 secretion in MDA-231 breast cancer cells (25). However, they reported that apigenin treatment caused a remarkable decrease at the mRNA and protein levels of urokinase plasminogen activator (u-PA), we failed to detect significant changes in u-PA mRNA expression level in Caski, MDA-231, and SK-Hep1 cell lines (data not shown). These results may reflect the importance of cell context in signal transduction pathways.

Several studies have identified signal transduction pathways such as ERK and p38 MAPK signaling pathways which were involved in regulation of MMP-2 and MMP-9 expression in malignant cells (25-28). In our system, PMAinduced MMP-9 expression was strongly attenuated by ERK inhibitor PD98059 or p38 inhibitor SB203580 treatment in Caski cells. In contrast, we failed to detect an increase of MMP-2 expression in PMA-treated Caski cells. However, PMA- prompting p38 activation was markedly suppressed by apigenin treatment, and PMA-induced ERK activation was partly weakened by apigenin treatment. Moreover, the combination treatment of SB203580 and apigenin inhibited MMP-9 activity and mRNA expression more compared with single treatment with SB203580 or apigenin (Fig. 4B). Restoration of $\mathrm{p} 38$ expression through transfection of a p38 expression vector partly increased PMA-mediated MMP-9 secretion blocked by apigenin treatment (Fig. 4C). These results suggested the possibility that apigenin might attenuate PMA-induced MMP-9 expression via p38-dependent pathways at transcriptional level.

Since a previous study demonstrated that dysregulation of the PI3K/Akt signaling pathway can lead to tumor progression (29), we checked whether apigenin treatment could inhibit PMA-induced Akt phosphorylation. Even though PMA did not activate Akt pathway in Caski cells, apigenin by itself suppressed the phosphorylated Akt levels (data not shown). Recently, it was reported that apigenin inhibited HGFpromoted invasive growth and metastasis involving blocking
PI3K/Akt pathway in several cancer cells including MDAMB-231, breast cancer cells, human hepatocellular carcinoma SKHep1 cells and human lung carcinoma A549 cells (30). Our result and that of the previous study suggested the possibility that down-regulation of the PI3K/Akt signaling pathway by apigenin could be developed into cancer chemopreventor. We also showed that apigenin inhibits PMA-induced MMP-9 mRNA expression and its activity in MDA-231 and SK-Hep1 cells, suggesting that apigenin may commonly regulate MMP-9 induction by PMA at transcriptional levels in different cancer cells. Further investigations are needed to clarify the precise mechanism(s) by which apigenin affects PMA-induced MMP-9 transcriptional regulation.

In conclusion, we showed that apigenin inhibited PMAinduced invasion and metastasis by reducing MMP-9 expression and secretion and mainly through the p38 MAPK pathways in Caski human cervical cancer cells. In addition, the inhibitory effect on MMP-9 induction by apigenin was also found in MDA-231 human breast cancer cells and SKHep1 human hepatoma cells. As evidenced from the above results, apigenin has the potential to be a powerful candidate in developing preventive agents for cancer metastasis and this beneficial effect may expand future research on anticancer properties of apigenin in vitro and in vivo.

\section{Acknowledgements}

This study was supported by the Yeungnam University research grants in 2008 .

\section{References}

1. Wittekind $\mathrm{C}$ and Neid M: Cancer invasion and metastasis. Oncology 69 (Suppl 1): 14-16, 2005.

2. Pantel K and Brakenhoff RH: Dissecting the metastatic cascade. Nat Rev Cancer 4: 448-456, 2004.

3. Steeg PS: Tumor metastasis: mechanistic insights and clinical challenges. Nat Med 12: 895-904, 2006.

4. Kleiner DE and Stetler-Stevenson WG: Matrix metalloproteinases and metastasis. Cancer Chemother Pharmacol 43: S42-S51, 1999.

5. Birkedal-Hansen H, Moore WG, Bodden MK, Windsor LJ, Birkedal-Hansen B, DeCarlo A and Engler JA: Matrix metalloproteinases: a review. Crit Rev Oral Biol Med 4: 197-250, 1993.

6. Mook OR, Frederiks WM and Van Noorden CJ: The role of gelatinases in colorectal cancer progression and metastasis. Biochim Biophys Acta 1705: 69-89, 2004.

7. Zucker S, Lysik RM, Zarrabi MH and Moll U: M(r) 92,000 type IV collagenase is increased in plasma of patients with colon cancer and breast cancer. Cancer Res 53: 140-146, 1993.

8. Bernhard EJ, Gruber SB and Muschel RJ: Direct evidence linking expression of matrix metalloproteinase 9 (92-kDa gelatinase/ collagenase) to the metastatic phenotype in transformed rat embryo cells. Proc Natl Acad Sci USA 91: 4293-4297, 1994.

9. Okada A, Tomasetto C, Lutz Y, Bellocq JP, Rio MC and Basset P: Expression of matrix metalloproteinases during rat skin wound healing: evidence that membrane type- 1 matrix metalloproteinase is a stromal activator of pro-gelatinase A. J Cell Biol 137: 67-77, 1997.

10. Sato H and Seiki M: Regulatory mechanism of $92 \mathrm{kDa}$ type IV collagenase gene expression which is associated with invasiveness of tumor cells. Oncogene 8: 395-405, 1993.

11. Waas ET, Lomme RM, DeGroot J, Wobbes T and Hendriks T: Tissue levels of active matrix metalloproteinase-2 and -9 in colorectal cancer. Br J Cancer 86: 1876-1883, 2002.

12. Lee PP, Hwang JJ, Murphy G and Ip MM: Functional significance of MMP-9 in tumor necrosis factor-induced proliferation and branching morphogenesis of mammary epithelial cells. Endocrinology 141: 3764-37673, 2000. 
13. Patel D, Shukla S and Gupta S: Apigenin and cancer chemoprevention: progress, potential and promise (Review). Int J Oncol 30: 233-245, 2007.

14. Overall CM, Wrana JL and Sodek J: Independent regulation of collagenase, $72-\mathrm{kDa}$ progelatinase, and metalloendoproteinase inhibitor expression in human fibroblasts by transforming growth factor-beta. J Biol Chem 264: 1860-1869, 1989.

15. Strongin AY, Collier I, Bannikov G, Marmer BL, Grant GA and Goldberg GI: Mechanism of cell surface activation of 72-kDa type IV collagenase. Isolation of the activated form of the membrane metalloprotease. J Biol Chem 270: 5331-5338, 1995.

16. Kharait S, Tran K, Yates C and Wells A: Cell motility in prostate tumor invasion and metastasis. In: Cell Motility in Cancer Invasion and Metastasis. Wells A (ed). Springer, pp301-338, 2006.

17. Kim D, Kim S, Koh H, Yoon SO, Chung AS, Cho KS and Chung J: Akt/PKB promotes cancer cell invasion via increased motility and metalloproteinase production. FASEB J 15: 1953-1962, 2001.

18. Stetler-Stevenson WG, Aznavoorian S and Liotta LA: Tumor cell interactions with the extracellular matrix during invasion and metastasis. Annu Rev Cell Biol 9: 541-573, 1993.

19. Chen PN, Kuo WH, Chiang CL, Chiou HL, Hsieh YS and Chu SC: Black rice anthocyanins inhibit cancer cell invasion via repressions of MMPs and u-PA expression. Chem Biol Interact 163: 218-229, 2006.

20. Shen KH, Hung SH, Yin LT, Huang CS, Chao CH, Liu CL and Shih YW: Acacetin, a flavonoid, inhibits the invasion and migration of human prostate cancer DU145 cells via inactivation of the p38 MAPK signaling pathway. Mol Cell Biochem 333: 279-291, 2010

21. Chien CS, Shen KH, Huang JS, Ko SC and Shih YW: Antimetastatic potential of fisetin involves inactivation of the PI3K Akt and JNK signaling pathways with downregulation of MMP-2/9 expressions in prostate cancer PC-3 cells. Mol Cell Biochem 333: 169-180, 2010.
22. Woo JH, Park JW, Lee SH, Kim YH, Lee IK, Gabrielson E, Lee SH, Lee HJ, Kho YH and Kwon TK: Dykellic acid inhibits phorbol myristate acetate-induced matrix metalloproteinase-9 expression by inhibiting nuclear factor kappa B transcriptional activity. Cancer Res 63: 3430-3434, 2003.

23. Hu XW, Meng D and Fang J: Apigenin inhibited migration and invasion of human ovarian cancer A2780 cells through focal adhesion kinase. Carcinogenesis 29: 2369-2376, 2008.

24. Czyz J, Madeja Z, Irmer U, Korohoda W and Hülser DF: Flavonoid apigenin inhibits motility and invasiveness of carcinoma cells in vitro. Int J Cancer 114: 12-18, 2005.

25. Lindenmeyer F, Li H, Menashi S, Soria C and Lu H: Apigenin acts on the tumor cell invasion process and regulates protease production. Nutr Cancer 39: 139-147, 2001.

26. Reddy KB, Krueger JS, Kondapaka SB and Diglio CA: Mitogen-activated protein kinase (MAPK) regulates the expression of progelatinase B (MMP-9) in breast epithelial cells. Int J Cancer 82: 268-273, 1999.

27. Gum R, Lengyel E, Juarez J, Chen JH, Sato H, Seiki M and Boyd D: Stimulation of $92-\mathrm{kDa}$ gelatinase B promoter activity by ras is mitogen-activated protein kinase kinase 1-independent and requires multiple transcription factor binding sites including closely spaced PEA3/ets and AP-1 sequences. J Biol Chem 271: 10672-10680, 1996.

28. Huang HP, Shih YW, Chang YC, Hung CN and Wang CJ: The chemoinhibitory effect of Mulberry anthocyanins on the melanoma metastasis involved in Ras/PI3K pathway. J Agric Food Chem 56: 9286-9293, 2008.

29. Lee WJ, Wu LF, Chen WK, Wang CJ and Tseng TH: Inhibitory effect of luteolin on hepatocyte growth factor/scatter factorinduced HepG2 cell invasion involving both MAPK/ERKs and PI3K-Akt pathways. Chem Biol Interact 160: 123-133, 2006.

30. Lee WJ, Chen WK, Wang CJ, Lin WL and Tseng TH: Apigenin inhibits HGF-promoted invasive growth and metastasis involving blocking PI3K/Akt pathway and 34 integrin function in MDAMB-231 breast cancer cells. Toxicol Appl Pharmacol 226: 178-191, 2008. 